\title{
Robotic Technologies for Non-Standard Design and Construction in Architecture
}

\author{
José Pedro Sousa ${ }^{1}$
}

Published online: 6 September 2016

(C) Kim Williams Books, Turin 2016

\begin{abstract}
In November 2015, the Faculty of Architecture at the University of Porto and the Institute for Systems and Computer Engineering, Technology and Science concluded a 2-year research project on the use of robotic fabrication technologies in architecture and building construction. Funded by the national Foundation of Science and Technology, this was a unique and vibrant experience on a new research field for the two institutions. This paper provides a brief description of the research project and its results.
\end{abstract}

Keywords Robotic technology · Construction techniques · Digital fabrication laboratories

\section{Introduction}

In November 2015, the Faculty of Architecture at the University of Porto (FAUP), its Center for Studies in Architecture and Urbanism (CEAU), and the Institute for Systems and Computer Engineering, Technology and Science (INESC TEC) concluded a 2-year research project on the use of robotic fabrication technologies in architecture and building construction. Funded by the Portuguese Foundation of Science and Technology (FCT), this was a unique and vibrant experience in a new research field for the two institutions. The present report provides a brief description about this research work, which gave rise to the new research group at FAUP called the Digital Fabrication Laboratory (DFL).

José Pedro Sousa

jsousa@arq.up.pt

1 Faculdade de Arquitectura da Universidade do Porto, Via Panorâmica S/N, 4150-564 Porto, Portugal 
The creation of the research project was motivated by two important observations at the global and local scales. On the global level, with the help of digital technologies, architecture in the twenty-first century can make use of new production possibilities that support geometric freedom and mass customization (Kolarevic 2003; Kolarevic and Klinger 2008). This trend towards flexible customization has been called 'non-standard architecture' (Cache 1995; Migayrou 2005), and has prompted building construction companies to embrace this paradigm in order to remain innovative in the present days. On the local level, facing this context, Portuguese industry is still attached to the standardization paradigm, which imposes limitations when responding to the increasing number of projects featuring intricate geometries and material solutions. This fact becomes more problematic because the current economic crisis has driven Portuguese companies towards internationalization, forcing them to compete against advanced global companies. Thus, the competitiveness of the Portuguese building industry is more than ever linked to its capacity to innovate at the global scale, responding to contemporary non-standard design challenges.

\section{The Research Project}

Given these global and local contexts, the research was planned by focusing on the most flexible digital manufacturing technology available today-the Industrial Robot - to investigate its potential to support non-standard modes of design and construction in architecture (Sousa 2015). Developed and widely implemented in other industries (such as the automotive industry), robots are advanced computerdriven machines, which, unlike other $\mathrm{CNC}$ equipment, can perform multiple fabrication actions (handling, milling, welding, folding, etc.) with different materials sizes and shapes. Since Fabio Gramazio and Matthias Kohler introduced them at the ETH Zurich in 2005 (Gramazio and Kohler 2007), a growing number of researchers and schools have started to explore the use of robots in architecture. When this research project proposal was submitted for funding in 2012, the Association for Robots in Architecture identified just eighteen established robotic architecture labs in the world, according to the 2012 version of the 'International Map of Robots in the Creative Industry (http://www.robotsinarchitecture.org/mapof-creative-robots). This research project thus established the first robotic architectural laboratory in Portugal, joining the small number of similar initiatives in the world at that time.

\section{The Structure}

To accomplish such endeavor, a multidisciplinary team was assembled, bringing together the FAUP, CEAU, and the INESC TEC institutions. The project was planned for 2 years, comprising a set of tasks related to: SURVEY, RESEARCH, MANAGEMENT AND MONITORING, and DIFFUSION (Table 1). 
Table 1 The structure of tasks

\begin{tabular}{lll}
\hline The structure of tasks & & \\
\hline I Survey & 1.1 Computational design & \\
& 1.2 Robotic technologies & \\
1.3 Architecture & \\
II Research & 2.1 Material & Additive fabrication \\
& 2.2 Design & Subtractive fabrication \\
& 2.3 Technology & Revising tradition \\
& & Innovative installation \\
III Management and & 3.1 Creation of the laboratory & Alternative robotic \\
monitoring & 3.2 Discussion & \\
IV Diffusion & 4.1 Website & \\
& 4.2 Catalogue & \\
& 4.3 Conferences, Workshops and Final & \\
& Exhibition & \\
&
\end{tabular}

The RESEARCH task, the central activity of the project, was subdivided in three parts into investigate Material, Design and Technology goals through a series of tests. Following additive, subtractive and formative fabrication methods, this tests explored different materials and robotic operations (Table 2).

\section{The Experience}

The Research Project started in July 2013. The first concerns were related with finding and adapting the space to set up the new laboratory and purchasing the industrial robot (Kuka KR120 R2700 HA). In the meantime, the team started with the three SURVEY tasks to help define the subsequent tests in the RESEARCH phase. On December 2013, the team from FAUP was officially accepted as the new research group at FAUP, and was called as the DFL. In the summer of 2014, the DFL moved to the renovated space and started the RESEARCH phase (Fig. 1).

With the material support from industrial partners (see the Acknowledgments at the end of this paper), cork, wood, concrete, bricks and expanded polystyrene (EPS) were selected to test a series of non-standard design and construction challenges. From the geometric point of view, these experiments addressed different topics that could be hardly materialized without the help of robotic technologies.

By exploring additive fabrication processes (i.e., through material assembly or deposition), the team investigated the assembly of irregular brick structures. In these constructions, standard bricks are positioned in differentiated positions in space to materialize both mathematical and figurative design concepts. As an example of the former interest, a team of master students from the Constructive Geometry course at FAUP designed the CG Column. Featuring central symmetry, this shape was 
Table 2 Research experiments

\begin{tabular}{lllll}
\hline Task & Name & Material & Fabrication type & Robotic process \\
\hline Material & Pixel Wall & Cork & Additive & Assembly \\
& Striated Wall & Wood & Additive & Assembly \\
& Brick Tower & Bricks (EPS) & Additive & Assembly \\
& CG Column & Bricks (EPS) & Additive & Assembly \\
& Face Bricks & Bricks (EPS) & Additive & Assembly \\
& Clover Wall & Cork & Subtractive & Water-jet cut/ \\
& & & & milling \\
& Diamond Screen & Wood & Subtractive & Milling \\
& Wooden & Wood & Subtractive & Milling \\
& Connections & & Subtractive & Milling \\
& Serpentine & Wood & Subtractive & Milling/hotwire \\
& Structure & & & cut \\
& Nasoni Keystone & Stone (EPS) & Subtractive/formative & Milling/hotwire \\
& & & & cut \\
& Ruled Concrete & Concrete + EPS & Additive & Assembly \\
Design & Hestnes Column & Bricks (EPS) & Subtractive/formative & Milling/hotwire \\
& CorkCrete Arch & Cork + Concrete & Ad \\
Technology & SPIDERobot & - & Assembly \\
\hline
\end{tabular}

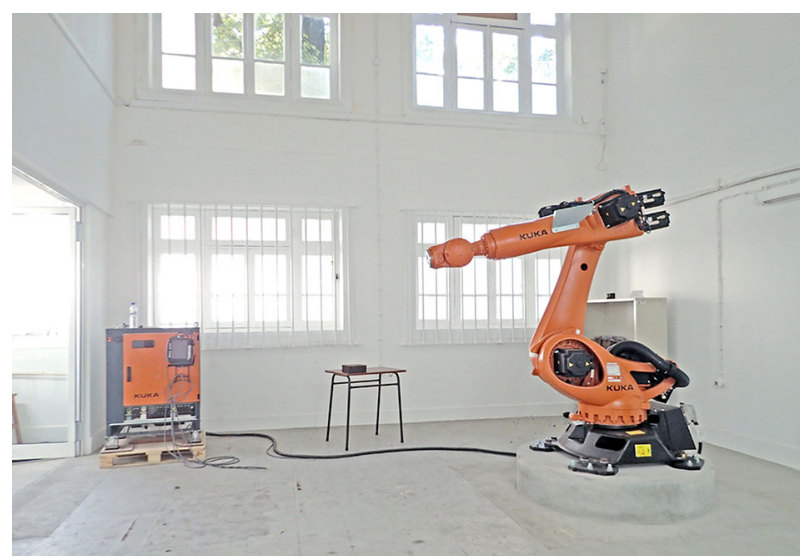

Fig. 1 The robot room setup at the DFL

generated by lofting two circles with a straight line in between. As an example of the latter approach, the Face OFFF was an intervention for an art festival, where a facial portrait was scanned and algorithmically converted into an assembly of bricks. In both scenarios, the irregular nature of their design geometry would be extremely hard to explain and fabricate using conventional drawings and manual bricklaying processes (Fig. 2). 

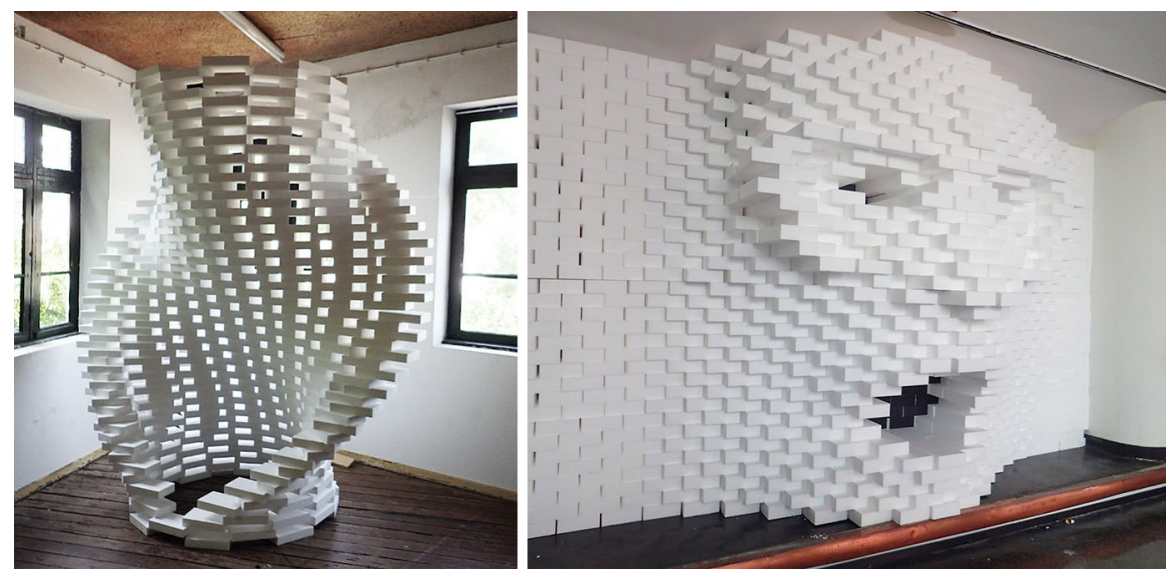

Fig. 2 The CG Column (left) and the Face OFFF (right)
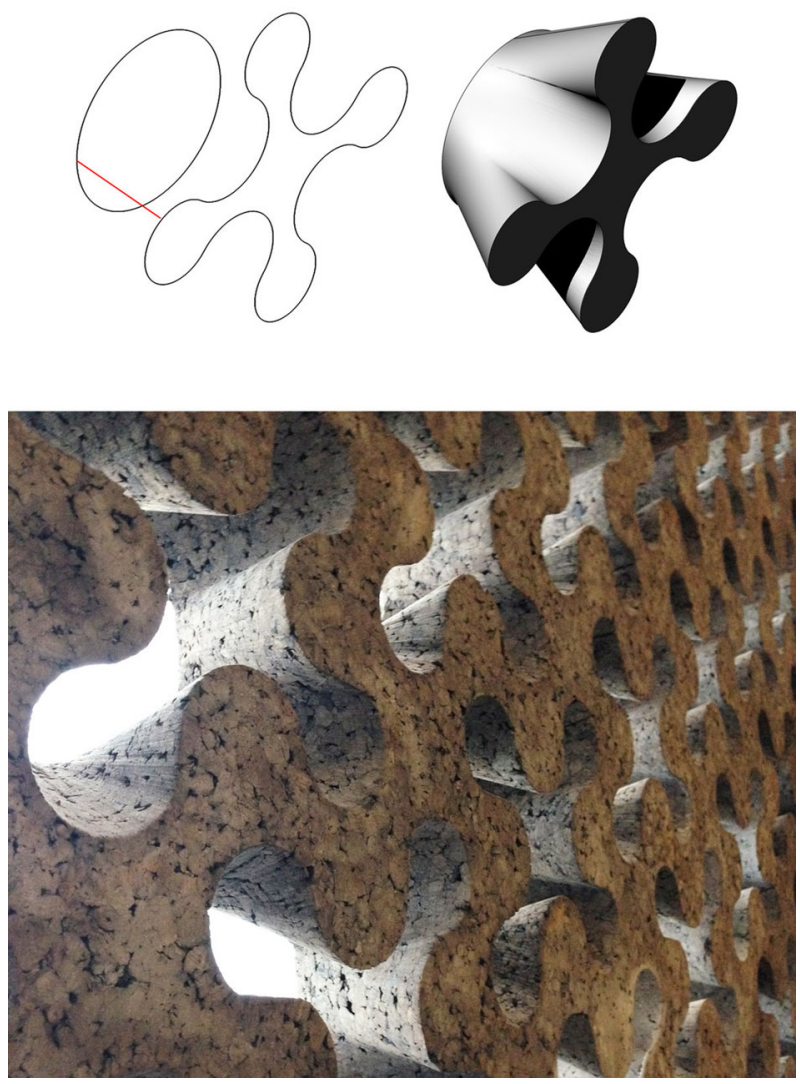

Fig. 3 The Clover Panel and the ruled surface geometry of its openings 

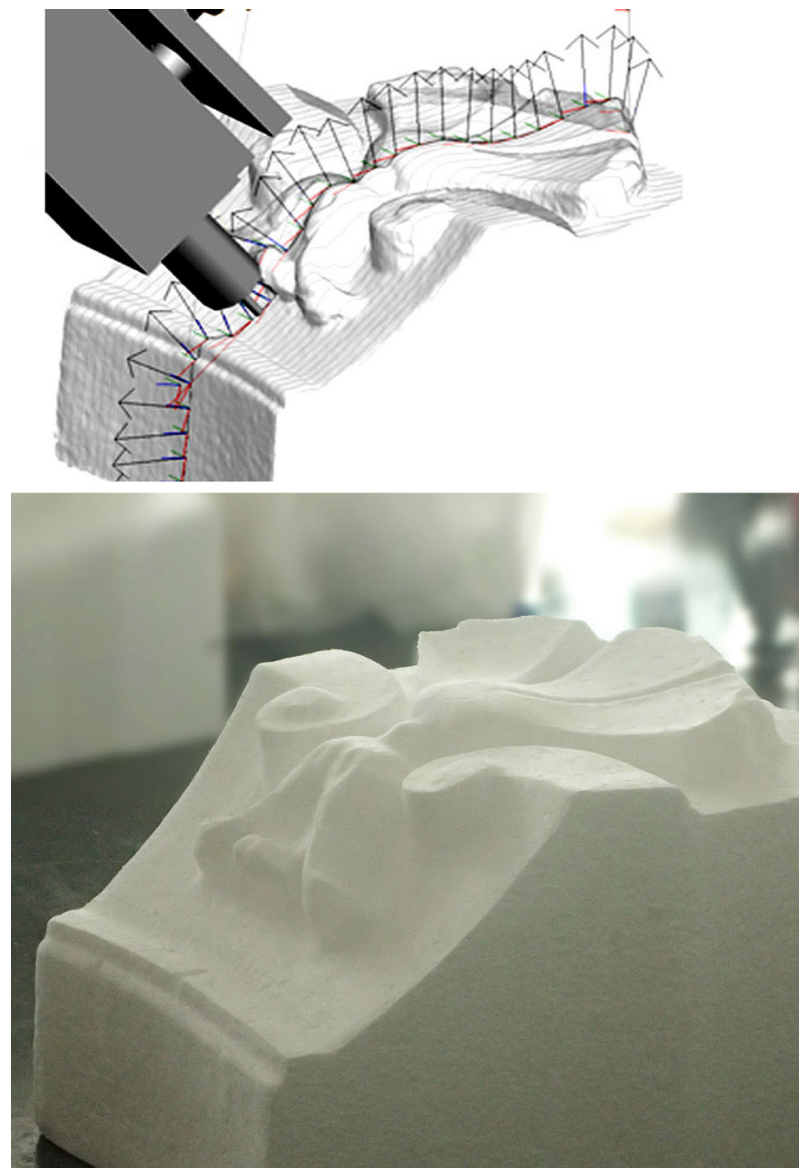

Fig. 4 The Nasoni Keystone with the freeform geometry of its decorative motif

By exploring subtractive fabrication processes (i.e., through cutting or removing material) the team explored both cutting and milling operations. Thus, in the Clover Wall, a set of perforated cork panels for a screen wall was produced using a waterjet cutting technology mounted in a robotic arm. The non-vertical undulating direction of the ruled-surface cuts required the flexibility of movements allowed by that machine (Fig. 3).

In a different way, by examining the application of robots in the field of heritage conservation, the Nasoni Keystone experiment addressed the material realisation of free-form geometries. By scanning the entrance's keystone of the Bishop's Palace in Porto, its form was converted into a point cloud, which gave origin to a mesh surface. From that geometric description, it became possible to program the complex robotic milling operations. Although this test used a foam block, the whole process could be directly transferred to stone cutting if one could supply a continuous cooling system. In both scenarios, the 6-axis freedom of 
movements allowed by the robot was essential to solve both subtractive fabrication operations (Fig. 4).

After 10 months, the tests for the Material sub-task of the RESEARCH part of the project were almost concluded, making way for those of DESIGN, with the 'Hestnes Column' and the 'CorkCrete Arch' works.

By looking to the tradition of brick architecture, the Hestnes Column project took as its point of departure the built work of Portuguese architect Raúl Hestnes Ferreira. Denoting the influence of Louis. Kahn, with whom he worked, the architect explored the expressive and structural potential of bricks in the design of domes, columns and walls. By developing a computational study on those typologies, the team presented to Hestnes a large set of parametric design variations, which attempted to extend his original brickwork solutions based on rotational, bilateral and translation symmetries, into the domain of geometric differentiation. With the help of 3D printed models, the architect chose a twisted column with variable openings in height to test the potential of its robotic fabrication (Fig. 5). The Hestnes Column was thus automatically assembled in $50 \mathrm{~min}$, which showed the possibility of new technologies to overcome the scarcity of patient and talented bricklaying workers (Fig. 6).

By looking into novel ideas, the CorkCrete Arch project investigated the combination of cork and glass-fiber reinforced concrete (GRC) to propose a new building system where the performative properties of the first material are combined with the structural ones of the latter (Sousa et al. 2016a). Working in close collaboration with the companies Amorim Isolamentos and Mota Engil, this concept was tested with the production of an arch. Based on a catenary curve to establish a form-based structural integrity, the geometry of the cork and the GRC panels was conceived to challenge different robotic fabrication processes (Fig. 7). Thus, the outer surface of the cork panels exhibits double curved geometry, with a customized engraved texture and variable slanted contours. To avoid an extra milling operation, the opposite surface is the original flat one. The outer surface of the GRC panels feature a ruled surface geometry, starting from straight lines in the ground feet and
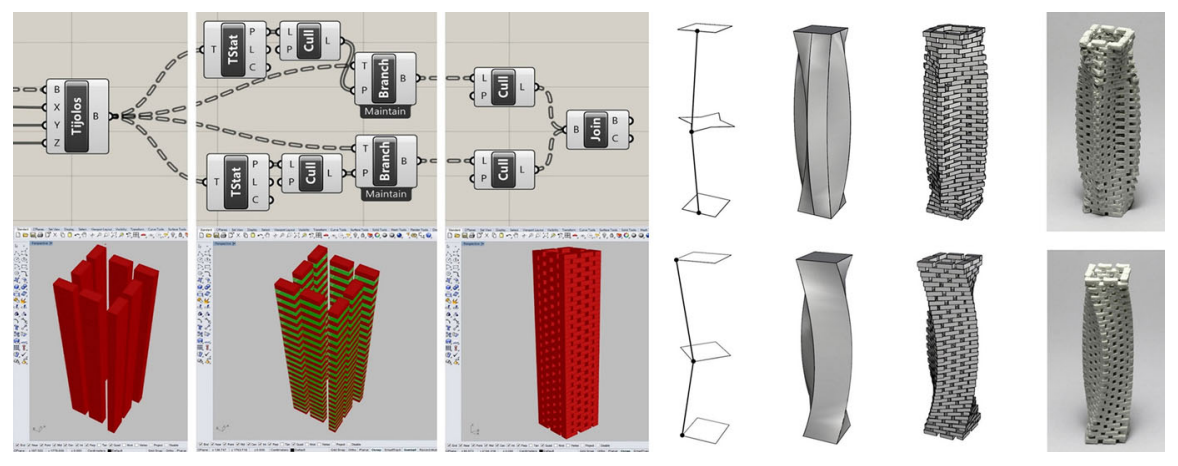

Fig. 5 The parametric design exploration of column designs using Rhinoceros and Grasshopper (left). The geometric primitives and rules, resulting surface, brickwork conversion, and 3D printed models of two of the many design columns that can be interactively generated by the definition (right) 


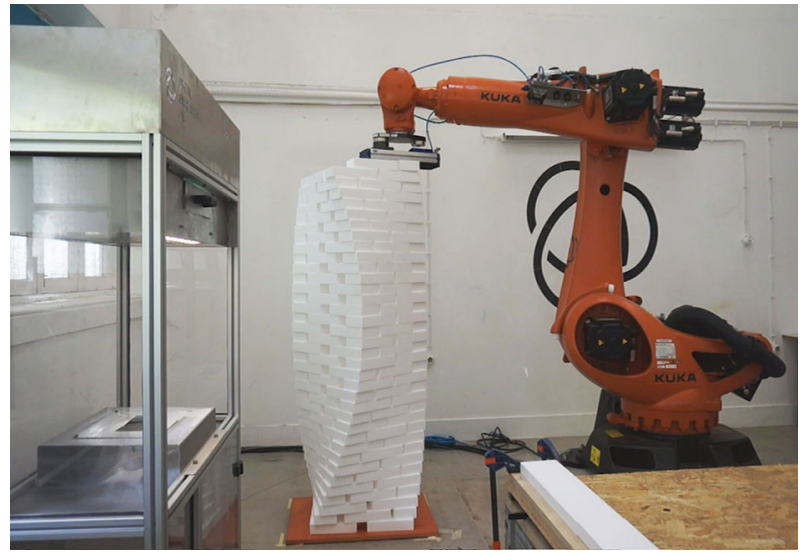

Fig. 6 The robotic assembly of the Hestnes Column near completion
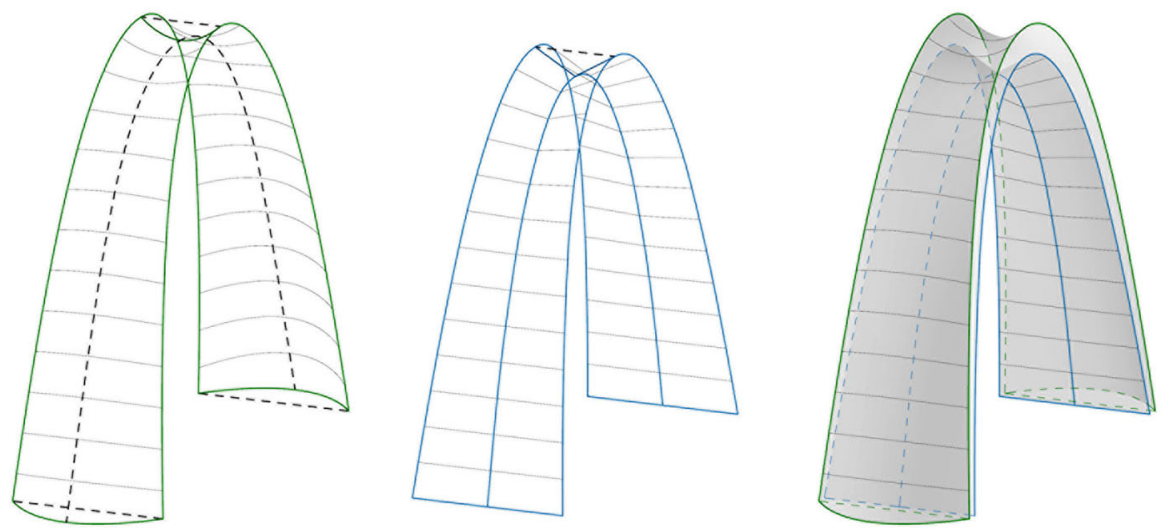

Fig. 7 The geometry of the Arch. In green, the double-curved surface of the cork panels; in blue, the ruled-surface of the GRC panels

folding into a protruding crease in the top of the arch. This condition defined the use of robotic hotwire to cut the surface and robotic milling to trim the edges of the EPS molds, for further manual GRC spraying. In the end, the two materials met together in an easily assembled arch structure (Fig. 8).

Finally, the TECHNOLOGY sub-task was carried out at INESC TEC in parallel with the previous ones. Looking for investigating an alternative robotic technology, the SPIDERobot is a functional prototype of a cable-robot based on a vision system, which is capable of performing pick-and-place operations on the construction site (Sousa 2016b). Because its four cables are always above the platform level, the working envelope of the SPIDERobot can be very large. A lightweight system that can be easily transported and assembled on site, it is a promising process to assist non-standard design concepts and construction strategies (Fig. 9). 

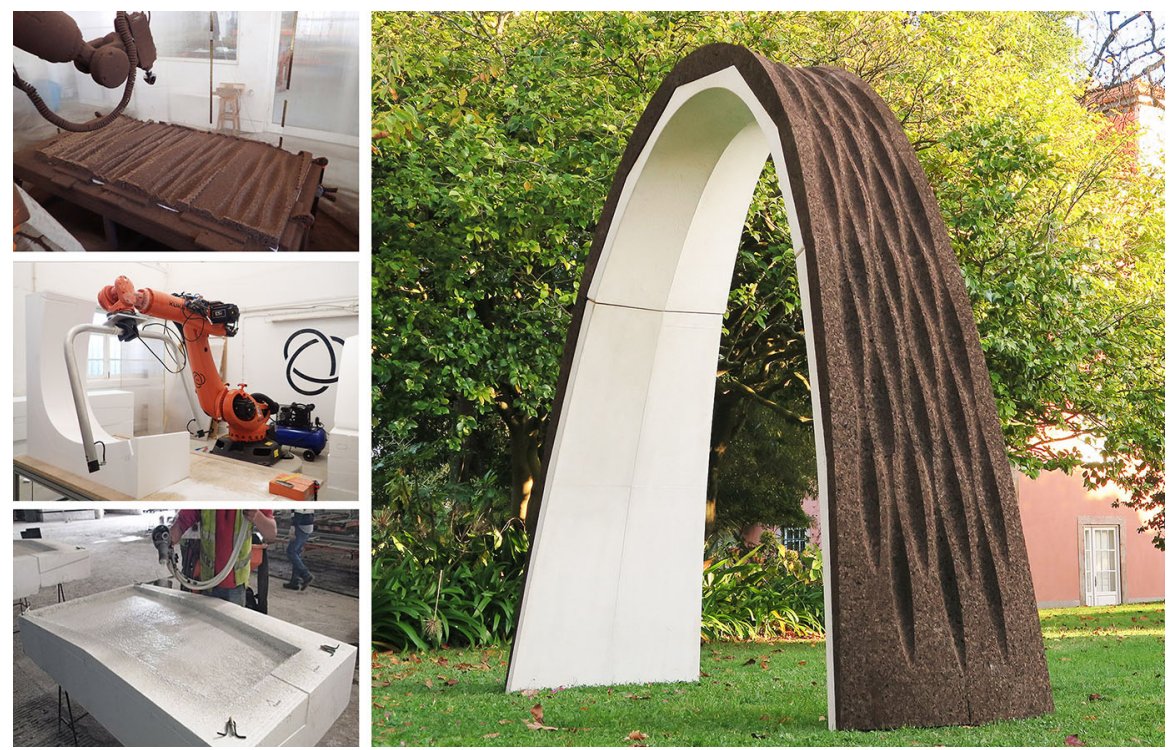

Fig. 8 The fabrication of the CorkCrete Arch (left) and its final installation at FAUP
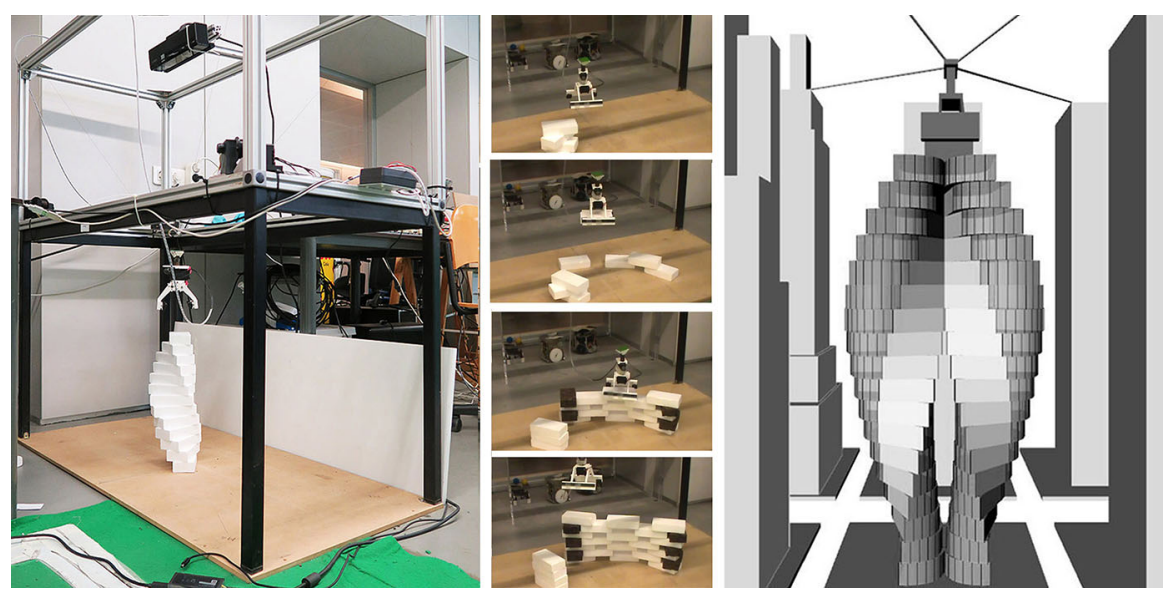

Fig. 9 The functional prototype of the SPIDERobot, and the simulation of its application in future onsite construction environments

The development of the research project was a very enriching period that resulted in the production of several digital and physical models, prototypes and installations. As the project proceeded, it was widely reported through a series of diffusing actions and events such as publications, conferences, exhibitions, videos, website, social media platforms, workshops, class assignments, visits, etc. The final results were presented in a public event in November 2015 (Fig. 10). 


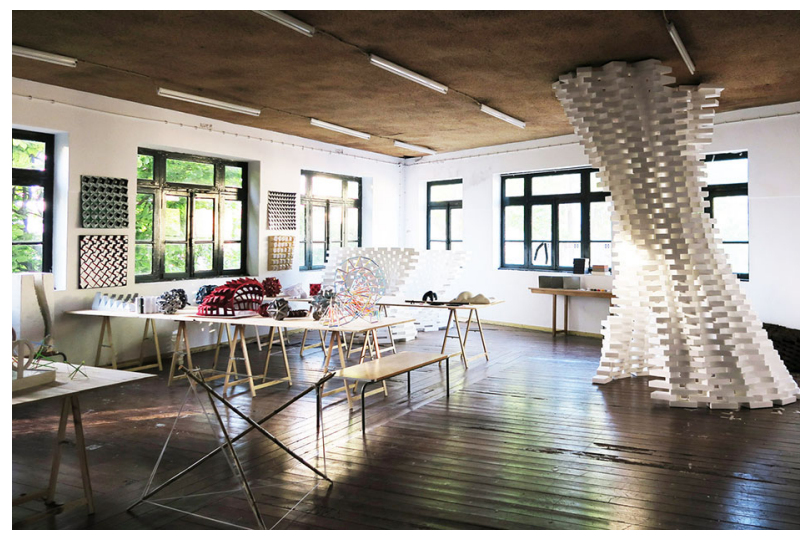

Fig. 10 An exhibition of the built experiments at the DFL

\section{Conclusion}

This research project made it possible to start a new research field in Portuguese architecture. The DFL was set at the FAUP, and is now actively participating in the worldwide discussion on the use of robotic technologies in architecture. Simultaneously, the INESC TEC extended its expertise on robotics into the field of building construction. In short, the wide spectrum of the RESEARCH tasks confirmed the potential of robotic technologies to address non- standard modes of design and construction in architecture, and triggered the interest of some industrial companies. The versatility of the industrial robot to work with different materials facing a wide range of geometric design and construction conditions was also remarkable. Among the different works, the CorkCrete arch and the SPIDERobot can be considered the most original and relevant contributions in the field. As a final note, it seems evident that the use of robots is an inevitable condition for the present and future of architecture and construction. However, more than simply being a means to materialize complex design aspirations, the full potential of robotic technologies may be related with the way they can trigger design imagination and efficiency to address the many difficult challenges of our contemporary world.

Acknowledgments This research project was funded by FEDER funds through the Operational Competitiveness Programme - COMPETE, and by national funds through the FCT-Foundation for the Science and Technology (Ref: PTDC/ATP-AQI/5124/2012), and was supported by industrial companies Amorim Isolamentos, Mota Engil, Valchromat and Cerâmica Vale da Gandara. I thank Profs. Dr. A. Paulo Moreira and Germano Veiga and their team at INESC TEC for their partnership in the research project, with a special emphasis on their leadership in the SPIDERobot work. I would also like to express my gratitude to the researchers Pedro Martins, Pedro Varela, Cristina Gasso-Palop and the rest of the team at DFL/CEAU/FAUP for their invaluable collaboration throughout the different tasks, and to Profs. Dr. Carlos Guimarães and João Pedro Xavier, Dean and Vice-Dean of FAUP, for their support for the emergence of this field of research in the school. 


\section{References}

Cache, Bernard. 1995. Earth Moves. Cambridge, MA: MIT Press.

Kolarevic, Branko, ed. 2003. Architecture in the Digital Age: Design and Manufacturing. New York: Spon Press.

Kolarevic, Branko and Kevin Klinger, eds. 2008. Manufacturing Material Effects: Rethinking Design and Making in Architecture. New York: Routledge.

Gramazio, Fabio and Matthias Kohler. 2007. Digital Materiality in Architecture. Baden: Lars Müller.

Migayrou, Frédéric, ed. 2005: Architectures Non-Standard. Paris: Center Georges Pompidou.

Sousa, José Pedro, ed. 2015. Robotic Technologies for Non-Standard Design and Construction in Architecture. Porto: FAUP, University of Porto.

(Sousa et al. 2016a) Sousa, José Pedro, Pedro Martins, Pedro de Azambuja Varela. 2016. The CorkCrete Arch project. In: Living Systems and Micro-Utopias: Towards Continuous Designing, Proceedings of the 21st CAADRIA - Computer Aided Architectural Design Research in Asia Conference, pp. 269-274. University of Melbourne.

(Sousa et al. 2016b) Sousa, José Pedro, Cristina Gasso Polap, Eduardo Moreira, Andry Maykol Pinto, José Lima, Paulo Costa, Pedro Costa, Germano Veiga, A. Paulo Moreira. 2016. The SPIDERobot: A Cable-Robot System for On-Site Construction in Architecture. In: Robotic Fabrication in Architecture, Art and Design 2016, Dagmar Reinhardt, Rob Saunders and Jane Burry, eds., pp.230-239. Springer.

José Pedro Sousa is an Assistant Professor at the Faculty of Architecture at the University of Porto (FAUP), where he founded and directs the Digital Fabrication Laboratory (DFL). He has a Ph.D. in Architecture from IST (Technical University of Lisbon), a Master in Genetic Architecture from ESARQUIC (International University of Catalonia) and a Licenciatura in Architecture from FAUP. He also studied as a Special student on Design and Computation at MIT (Massachusetts Institute of Technology, USA) and was a Visiting Scholar in Architecture at the UPenn (University of Pennsylvania, USA). With an interest in exploring new conceptual and material opportunities emerging from the use of computational design, digital fabrication and robotic technologies, since 1999 his activity has merged the realms of teaching, research and design practice. He was awarded the 2005 FEIDAD Outstanding Award and the 2009 Young Research Award of the Technical University of Lisbon. 